\title{
APLICAÇÃO DE DIETHATYL PARA O CONTROLE DE PLANTAS DANINHAS EM CULTURA DE ALGODOEIRO HERBÁCEO
}

\section{RESUMO}

Para conhecer a ação do herbicida diethatyl [N-cloroacetil -N-(2,6-dietilfenil) glicine] no controle de plantas infestantes de cultura de algodão herbáceo foram conduzidos sete experimentos de campo nos anos de 1974 e 1975 . Os ensaios foram instalados em diversos tipos de solos onde diethatyl foi aplicado em pré-plantio incorporado e em pré-emergência e foi comparado com herbicidas já conhecidos e comumente empregados em algodoeiros e, ainda, com alguns novos herbicidas. Es se produto mostrou-se eficiente no controle de gramineas e de algumas plantas daninhas de folhas largas e não foi prejudicial às plantas de atgodão e à sua produção.

UNITERMOS: diethatyl, herbicida, plantas daninhas, algodão.

\section{SUMMARY}

USE OF DIETHATYL TO CONTROL WEEDS IN HERBACEUSCOTTON CROP

Seven field trials were conducted in 1974 and 1975 to determine the efficiency of the herbicide diethatyl for weed control in herbaceus cotton. Trials were carried out on various types of soil, and diethatyl was applied in pre-plant incorporated and preemergence. Standard herbicides normally used in cotton and some new herbicides were also included. This compound showed efficacy in controlling gramineae and also some broad leaves weeds and did not cause damage to the crop nor affected yield.

KEYWORDS: Die thatyl, herbicide, weeds, cotton.

\section{INTRODUÇÃO}

Entre as técnicas culturais empregadas em programa de controle de plantas daninhas que comumente infes-

\section{L.S.P. CRUZ* \& L. LEIDERMAN*}

* Pesquisadores Científicos do Instituto Biológico, Seção de Herbicidas. C.Postal 70 - 13.100 Campinas, SP.

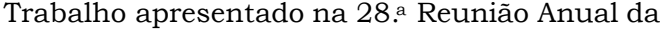
SBPC, em Brasilia, DF, 1976.

Recebido para publicação em 21 de janeiro de 1980.

tam algodoais, destaca-se aquela em que são usados produtos químicos, os herbicidas. Tem contribuído para o crescente aumen to do uso de herbicidas em culturas de algodão a escassez de mão de obra e a ação mais eficiente, rápida e prolongada daqueles produtos quando comparados com a capina manual ou mecânica. Trabalhos anteriores $(1,6,15,16)$ mostram as possibilidades e vantagens do uso de herbicidas residuais em culturas de algodão.

Diversos autores $(4,5,9,11)$ têm determinado os primeiros 30 a 60 dias como os mais criticos para os algodoeiros, quando então, as plantas infestantes fazem maior concorrência à cultura, época em que os herbicidas residuais encontram-se em sua plena ação.

Em consequência do crescente uso de herbicidas, novos produtos vêm sendo elaborados nos laboratórios especializados, visando superar em eficiência os já existêntes $(2,7,8,15)$.

Com o aparecimento de mais um produto novo, o Instituto Biológico iniciou um estudo com a condução de sete ensaios de campo, em 1974 e em 1975, para conhecer sua ação, em diferentes doses, aplicado em pré-plantio incor porado e em pré-emergência, sobre algumas plantas infestantes de culturas de algodão, comparando-o com outros herbicidas ainda não conhecidos, bem como com herbicidas anteriormente testados com êxito $(2,7,10,15,16)$. 


\section{MATERIAIS E MÉTODOS}

O produto testado é um concentrado emulsionável contendo $480 \mathrm{~g} / 1$ de diethatyl ( $\left.{ }^{1}\right)$.

O delineamento experimental escolhido foi o de blocos ao acaso, com quatro repetições, com parcelas de cinco linhas de algodoeiros, com 5,OOm de comprimento, com área útil formada pelas três linhas centrais. A variedade de algodão plantada em todos os experimentos foi a IAC 13-1, com espaçamento de 1,00 $\mathrm{m}$ entre linhas e $0,10 \mathrm{~m}$ entre plantas. A semeadura do algodão foi feita no mesmo dia da aplicação dos herbicidas, gastando-se $40 \mathrm{~kg} /$ ha de sementes.

Os herbicidas foram aplicados em pré-plantio incorporado e em pré-emergência das plantas daninhas e da cultura, na área total de cada parcela com pulverizador costal, manual, munido de bico de iato em leque 80.03 trabalhando a $2,80 \mathrm{~kg} / \mathrm{cm}^{2}$ de pressão, com um gasto de calda correspondente a $4801 /$ ha. A incorporação dos herbicidas ao solo, nos tratamentos em pré - plantio incorporado, foi realizada com o auxilio de grade de discos trabalhando a uma profundidade de $0,15 \mathrm{~m}$.

Para a avaliação da eficiência do produto experimentado foi considerada a porcentagem de controle das plantas infestantes, tomada em relação à testemunha sem herbicida, pela contagem de plantas daninhas aos 30 dias após a aplicação dos herbicidas, em duas amostras por parcela, em área de $0,50 \mathrm{~m}^{2}$ $(1, \mathrm{OOm} \times 0,50 \mathrm{~m})$ cada, representativa da infestação média. As principais plantas daninhas que formavam a população natural das áreas dos experimentos eram: capim carrapicho - Cenchrus echinatus L., capim-decolchão - Digitaria horizontalis Willd, capim-pé-degalinha - Eleusine indica (L.) Gaertn, trapoeraba Commelina elegans H.B.K., carrapicho-do-campo Acanthospermum australe (Loef) O. Kuntze, carrapichodecarneiro - Acanthospermum hispidum DC., mentrasto - Ageratum conyzoides L., picão preto - Bi-dens pilosa L., erva palha - Blainvillea rhomboidea Cass., falsa poaia Borreria alata (Aubl.) DC, falsa serralha - Emilia sonchifolia (L) DC, cipó - Ipomoea sp, poaia branca Richardia brasiliensis Gomez e guanxumas - Sida spp.

(1) Desenvolvido por Hercules Incorporated, EUA.
Procedeu-se a observação sobre possiveis sintomas característicos de fitotoxicidade causado pelos herbicidas sobre a cultura e se fez a contagem do número de plantas de algodão, logo após a colheita.

No quadro 1 são apresentados os mu nicipios em que foram desenvolvidos os en saios, as datas de aplicação dos herbicidas e do plantio do algodão, bem como o modo de aplicação e a data da colheita.

Foi estudada a ação dos seguintes herbicidas:

Experimentos 1 e 2:

Diethatyl a $2,00 \mathrm{~kg}, 4,00 \mathrm{~kg}$ e $6,00 \mathrm{~kg} / \mathrm{ha}(\mathrm{I})$

Nitrofluorfen [2-cloro-1-(4 nitrofenoxi-4-trifluormetil benzeno)] a $0,25 \mathrm{~kg}, 0,50 \mathrm{~kg}$ e 0,75 $\mathrm{kg} / \mathrm{ha}(2)$

Alachlor [2-cloro-2',6'-dietil-N-(metoximetil) acetanilida)] a $2,50 \mathrm{~kg} / \mathrm{ha}(3)$

Experimentos 3 e 4 :

Diethatyl a $2,00 \mathrm{~kg}, 4,00 \mathrm{~kg}$ e $6,00 \mathrm{~kg} / \mathrm{ha}$.

Nitrofluorfen a $0,25 \mathrm{~kg}, 0,50 \mathrm{~kg}$ e $0,75 \mathrm{~kg} / \mathrm{ha}$

Pendimethalin [N-(1-etilpropil) - 2, 6-dinitro-3,4xilidine] a $1,20 \mathrm{~kg} / \mathrm{ha}$ (4) Trifluralin

[(a, a, a, trifluoro-2,6-dinitro-N-N-dipropiltoluidina)] a $1,00 \mathrm{~kg} / \mathrm{ha}(5)$

Mistura de nitrofluorfen a $0,25 \mathrm{~kg} /$ ha e trifluralin a $0,50 \mathrm{~kg} / \mathrm{ha}$.

Experimentos 5, 6 e 7:

Diethatyl a 2,00 kg, 4,00 kg e 6,00 kg/ha no Exp. 5 e a $2,00 \mathrm{~kg}, 3,00 \mathrm{~kg} \mathrm{e} 4,00 \mathrm{~kg} / \mathrm{ha}$ nos Exps. 6 e 7 .

Alachlor a $2,50 \mathrm{~kg} / \mathrm{ha}$.

Trifluralin a $1,00 \mathrm{~kg} / \mathrm{ha}$.

$\mathrm{Em}$ todos os experimentos foi incluído um tratamento testemunha, sem herbicida, capinado a enxada.

No quadro 2 são apresentadas as características químicas (1) e físicas (2) dos solos das áreas aproveitadas com os ensaios:

\section{1) Antor, com $480 \mathrm{~g} / \mathrm{l}$ de ingrediente attwo (i.a.) (ग) Bimitar, com 240 gr/l de t,a. \\ (3) Laço, com $480 \mathrm{~g} / \mathrm{h}$ de La.}

(9) Herbadox $390 \mathrm{z}$, formulaçes brasileira e norte-americans, am bas com $330 \mathrm{~g} /$ de L.

(3) Treflan e Trinurex, ambos com 480 g/ de $1 . \mathrm{a}$.

QUADRO 1. Dados sobre os experimentos realizados.

\begin{tabular}{|c|c|c|c|c|}
\hline Experimento & Município & $\begin{array}{l}\text { Modo de aplicapio dos } \\
\text { herbicidas }\end{array}$ & $\begin{array}{l}\text { Data de aplicaçio dos } \\
\text { herbicidas e do phantio }\end{array}$ & $\begin{array}{l}\text { Datn da } \\
\text { collheita }\end{array}$ \\
\hline $\begin{array}{l}1 \\
2 \\
3 \\
4 \\
5 \\
6 \\
7\end{array}$ & $\begin{array}{l}\text { Plrassununga } \\
\text { Araras } \\
\text { Plrassununga } \\
\text { Araras } \\
\text { Moed Mindm } \\
\text { Plrassununga } \\
\text { Casa Branca }\end{array}$ & $\begin{array}{l}\text { Pré-emergêncla (PRE) } \\
\text { Pré-emergêncla (PRE) } \\
\text { Pré-plantio incorp. (PPI) } \\
\text { Pró-plantio incorp. (PPI) } \\
\text { Pré-em. e pró-pl. (PRE e PPI) } \\
\text { Pré-em. e pré-pl. (PRE e PPI) } \\
\text { Pré-em. e pró-pl. (PRE e PP) }\end{array}$ & $\begin{array}{l}14-10-74 \\
24-10-74 \\
10-10-74 \\
24-10-74 \\
25-11-74 \\
16-10-75 \\
05-11-75\end{array}$ & $\begin{array}{l}20-03-75 \\
08-04-75 \\
23-03-75 \\
08-04-75 \\
14-05-75 \\
29-03-76 \\
10-05-76\end{array}$ \\
\hline
\end{tabular}


QUADRO 2. Características químicas e físicas dos solos das áreas dos diferentes experimentos.

\begin{tabular}{lccrrrrr}
\hline Experimento & 1 & 2 & 3 & 4 & 5 & 6 & 7 \\
\hline pH internacional & 5,90 & 5,55 & 5,97 & 5,55 & 5,80 & 6,00 & 5,50 \\
MO (\%) (3) & 2,75 & 5,50 & 3,44 & 5,50 & 3,80 & 2,50 & 3,60 \\
Argilla (\%) & 37,50 & 65,00 & 35,00 & 65,00 & 43,70 & 32,50 & 45,00 \\
Limo (\%) & 2,50 & 10,00 & 5,00 & 10,00 & 6,30 & 3,70 & 3,70 \\
Areia fina (\%) & 36,00 & 19,10 & 41,40 & 19,10 & 24,30 & 33,00 & 26,40 \\
Arein grossa (\%) & 24,00 & 5,90 & 18,50 & 5,90 & 25,70 & 30,80 & 24,90 \\
Tipo de solo (Textura) & barrento & muito & barrento & muito & argiloso & barrento & argilloso \\
& & argiloso & & argiloso & & &
\end{tabular}

(1) Análises efetuadas pela Seção de Fertillidade de Solos, Instituto Agronômico de Campinas.

(2) Análitises efetuadas pela Seção de Pedologia, Instituto Agronômico de Campinas.

(3) $\mathrm{MO}=1,72 \times \mathrm{C}$.

\section{RESULTADOS E DISCUSSÃo}

\section{Experimento 1}

Os dados de porcentagem de controle de plantas daninhas estão contidos no quadro 3 e os de número de plantas e de produção de algo dão em caroço, no quadro 5 .

\section{Experimento 2}

Os resultados obtidos de porcentagem de controle de plantas daninhas estão no quadro 4 e os de produção no quadro 5.

\section{Experimento 3}

No quadro 6 estão os dados de porcentagem de controle das infestantes que apareceram neste experimento, e no quadro 8 os dados de produção de algodão em caroço.

Experimento 4

Os dados de porcentagem de controle de plantas daninhas estão no quadro 7. O número das principais plantas daninhas incidentes foi pequeno, com um total de $180 / \mathrm{m}^{2}$, representado por apenas três espécies: $D$. horizontalis, $B$. rhomboidea e E. sonchifolia.

No quadro 8 estão os números de plantas e as produções de algodão.

\section{Experimento 5}

Os dados de porcentagem de controle das infestantes estão no quadro 9. $\mathrm{O}$ número total das principais plantas daninhas que apareceram foi de $922 / \mathrm{m}^{2}$, com predominância de A. hispidum, que incidiu com $75,2 \%$ desse total.

Os dados referentes ao número de plantas de algodão por ocasião da colheita, e a produção, estão no quadro 10.

Experimento 6

Os dados referentes ao controle de plantas daninhas oferecido pelos herbicidas experimentados estão no quadro 11 e a produção de algodão em caroço no quadro 13.

Experimento 7

$\mathrm{O}$ número das principais plantas daninhas que incidiram foi representativo, ou seja $2330 / \mathrm{m}^{2}$, sendo que quase $50 \%$ desse total era constituído por $D$. horizontalis (Quadro 12).

Os dados do número de algodoeiros e de produção de algodão em caroço estão contidos no quadro 13 .

Estudo do conjunto dos experimentos:

A frequência de aparecimento das principais plantas daninhas nos experimentos foi a seguinte: C. echinatus, $C$. elegans, $A$. australe, A. hispidum, $B$. pilosa, B. rhomboidea e B. alata, em apenas um experimento; Ipomoea sp., em dois; E. indica, $A$. conyzoides, $R$. brasiliensis e Sida spp, em três; $E$. sonchifolia, em cinco; e D. horizontalis, em seis. Verifica-se que as gramineas mais frequentes foram $D$. horizontalis e E. indica; e, as plantas daninhas de folhas largas que apareceram mais vezes foram $E$. sonchifolia, $A$. conyzoides, $R$. brasiliensis e Sida spp.

Em todos os ensaios, diethatyl conseguiu controlar eficientemente as gra- 
Quadro 3. Porcentagem de controle, 30 dias apbs a aplicaçấo dos herbicidas em próemergènela, em ensaio com algodìo, em Pirassununga, SP.

\begin{tabular}{|c|c|c|c|c|c|c|c|c|c|}
\hline \multirow{2}{*}{ Herbicida } & \multirow{2}{*}{$\begin{array}{l}\text { Ingrediente } \\
\text { ativo } \\
\text { (kg/ha) }\end{array}$} & \multicolumn{8}{|c|}{ Porcentagem de controle } \\
\hline & & $\begin{array}{c}\text { Digitoria } \\
\text { horizontalis }\end{array}$ & $\begin{array}{l}\text { Cenchrus } \\
\text { echinatus }\end{array}$ & $\begin{array}{l}\text { Eleustine } \\
\text { indica }\end{array}$ & Sida spp & $\begin{array}{l}\text { Bidens } \\
\text { pllosa }\end{array}$ & $\begin{array}{c}\text { Ipomoes } \\
\text { sp }\end{array}$ & $\underset{\text { Emenilifolia }}{\text { sonch }}$ & Controle genal \\
\hline Diethaty1 & $\begin{array}{l}2,00 \\
4,00 \\
6,00\end{array}$ & $\begin{array}{l}97,2 \\
99,6 \\
99,4\end{array}$ & $\begin{array}{l}68,1 \\
92,7 \\
97,1\end{array}$ & $\begin{array}{r}98,3 \\
100,0 \\
100,0\end{array}$ & $\begin{array}{r}0,0 \\
53,5 \\
73,2\end{array}$ & $\begin{array}{r}0,0 \\
10,7 \\
77,4\end{array}$ & $\begin{array}{l}30,7 \\
68,8 \\
64,1\end{array}$ & $\begin{array}{r}0,0 \\
8,6 \\
67,2\end{array}$ & $\begin{array}{r}63,3 \\
77,6 \\
89,4\end{array}$ \\
\hline Nitrofluorfen & $\begin{array}{l}0,25 \\
0,50 \\
0,75\end{array}$ & $\begin{array}{l}80,4 \\
78,3 \\
75,9\end{array}$ & $\begin{array}{l}58,0 \\
81,1 \\
82,6\end{array}$ & $\begin{array}{r}88,1 \\
96,6 \\
100,0\end{array}$ & $\begin{array}{l}0,0 \\
0,0 \\
9,8\end{array}$ & $\begin{array}{l}32,1 \\
30,0 \\
59,5\end{array}$ & $\begin{array}{l}64,1 \\
71,8 \\
76,9\end{array}$ & $\begin{array}{r}20,7 \\
0,0 \\
0,0\end{array}$ & $\begin{array}{l}40,0 \\
43,2 \\
61,5\end{array}$ \\
\hline Alachlor & 2,50 & 98,7 & 84,0 & 100,0 & 43,7 & 80,9 & 33,3 & 0,0 & 77,0 \\
\hline Testemunha $\left({ }^{*}\right)$ & - & 535 & 69 & 59 & 142 & 84 & 78 & 58 & 1025 \\
\hline
\end{tabular}

(•) Número de plantas daninhas por metro quadrado. 
Quadro 4. Porcentagem de controle, 30 dias após a aplicação dos herbicidas em pré -emergência, em ensaio com algodão em Araras, SP.

\begin{tabular}{llllll}
\hline \multirow{2}{*}{ Herbicida } & $\begin{array}{l}\text { Ingrediente } \\
\text { ativo } \\
\text { (kg/ha) }\end{array}$ & $\begin{array}{c}\text { Pigitaria } \\
\text { hortzontalis }\end{array}$ & $\begin{array}{l}\text { Agentum } \\
\text { conyzoides }\end{array}$ & $\begin{array}{c}\text { Emilia } \\
\text { sonchifolia }\end{array}$ & Controle genl \\
\cline { 3 - 6 } & & 94,6 & 58,0 & 6,6 & 55,1 \\
Diethatyl & 2,00 & 97,3 & 65,0 & 0,0 & 56,4 \\
& 4,00 & 98,6 & 75,0 & 18,1 & 66,8 \\
Nitrofluorfen & 6,00 & 54,6 & 55,0 & 0,0 & 38,1 \\
& 0,25 & 62,6 & 55,0 & 0,0 & 39,8 \\
Alachlor & 0,50 & 74,6 & 62,0 & 25,7 & 56,1 \\
Testemunha & 0,75 & 94,6 & 72,0 & 38,3 & 69,7 \\
\hline \hline
\end{tabular}

(*) Número de plantas daninhas por metro quadrado.

mineas, com resultados satisfatórios para as doses de $3,00 \mathrm{~kg}$ e 4,00 kg/ha. O estudo do controle de plantas daninhas de folhas largas oferecido por diethatyl mostra ter havido uma certa diferença nos resultados encontrados. Referidas diferenças são originadas pela maior dificuldade de ação desses herbicidas sobre essas plantas daninhas relacionadas com condições climáticas e tipos de solos. Segundo Blanco e Godoy (3) a média anual das precipitações pluviometricas nos municipios em que foram conduzidos os experimentos é da ordem de 1300 milimetros, com variabilidade de $\pm 250 \mathrm{~mm}$, suficiente para a eficácia dos herbicidas. De modo geral, houve ocorrência de chuvas num intervalo de sete dias antes e sete dias após a aplicação dos produtos no solo, portanto dentro das especificações dadas por Splittstoesser e Derscheid (17) para o bom funcionamento de alguns herbicidas.

As temperaturas obtidas nos ensaios por ocasião da aplicação dos herbicidas (Quadro 14) variaram de $22,2^{\circ} \mathrm{C}$ a $34,8^{\circ} \mathrm{C}$ quando medidas a $1,00 \mathrm{~m}$ acima do solo. Quando tomadas a $0,025 \mathrm{~m}$ de profundidade do solo houve variação de $22,2^{\circ} \mathrm{C}$ a $43,0^{\circ} \mathrm{C}$, podendo constituir

Quadro 5. Número de plantas e produção de algodão em caroço em ensaios com herbicidas em pré-emergência, em Pirassununga-SP, e em Araras, SP.

\begin{tabular}{|c|c|c|c|c|c|}
\hline \multirow{2}{*}{ - Herbicida } & \multirow{2}{*}{$\begin{array}{l}\text { Ingrediente } \\
\text { ativo } \\
\text { (kg/ha) }\end{array}$} & \multicolumn{2}{|c|}{ Pirassunung } & \multicolumn{2}{|c|}{ Arans } \\
\hline & & $\begin{array}{l}\text { Número de } \\
\text { plantas }\end{array}$ & $\begin{array}{l}\text { Produçĩo } \\
\text { (kg) }\end{array}$ & $\begin{array}{l}\text { Número de } \\
\text { phntas }\end{array}$ & $\begin{array}{l}\text { Produçito } \\
\text { (kg) }\end{array}$ \\
\hline Diethatyl & $\begin{array}{l}2,00 \\
4,00 \\
6,00\end{array}$ & $\begin{array}{l}570 \\
559 \\
564\end{array}$ & $\begin{array}{l}8,250 \\
7,870 \\
7,750\end{array}$ & $\begin{array}{l}685 \\
667 \\
689\end{array}$ & $\begin{array}{r}9,500 \\
9,500 \\
10,000\end{array}$ \\
\hline Nitrofluorfen & $\begin{array}{l}0,25 \\
0,50 \\
0,75\end{array}$ & $\begin{array}{l}571 \\
569 \\
576\end{array}$ & $\begin{array}{l}7,870 \\
7,870 \\
8,120\end{array}$ & $\begin{array}{l}675 \\
664 \\
670\end{array}$ & $\begin{array}{l}9,250 \\
9,500 \\
9,750\end{array}$ \\
\hline $\begin{array}{l}\text { Alachlor } \\
\text { Testemunha }\end{array}$ & $\begin{array}{c}2,50 \\
-\end{array}$ & $\begin{array}{l}571 \\
573\end{array}$ & $\begin{array}{l}8,000 \\
7,870\end{array}$ & $\begin{array}{l}678 \\
683\end{array}$ & $\begin{array}{l}9,750 \\
9,000\end{array}$ \\
\hline
\end{tabular}


Quadro 6. Porcentagem de controle, 30 dias após a aplicação dos herbicidas em pré-plantio incorporado, em ensaio com algodão, em Pirassununga, SP.

\begin{tabular}{|c|c|c|c|c|c|c|c|}
\hline \multirow{2}{*}{ Herbicida } & \multirow{2}{*}{$\begin{array}{l}\text { Ingrediente } \\
\text { ativo } \\
\text { (kg/ha) }\end{array}$} & \multicolumn{5}{|c|}{ Porcentagem de controle } & \multirow[b]{2}{*}{$\begin{array}{c}\text { Controle } \\
\text { genl }\end{array}$} \\
\hline & & $\begin{array}{c}\text { Digitaria } \\
\text { horizontalis }\end{array}$ & $\begin{array}{l}\text { Eleusine } \\
\text { indica }\end{array}$ & $\begin{array}{l}\text { Richardia } \\
\text { brasiliensts }\end{array}$ & $\begin{array}{l}\text { Ageratum } \\
\text { conyzoides }\end{array}$ & $\begin{array}{l}\text { Emilia } \\
\text { sonchifolla }\end{array}$ & \\
\hline Diethatyl & $\begin{array}{l}2,00 \\
4,00 \\
6,00\end{array}$ & $\begin{array}{r}98,2 \\
98,2 \\
100,0\end{array}$ & $\begin{array}{r}94,2 \\
93,5 \\
100,0\end{array}$ & $\begin{array}{l}79,2 \\
81,5 \\
81,5\end{array}$ & $\begin{array}{l}24,8 \\
46,3 \\
53,6\end{array}$ & $\begin{array}{l}24,2 \\
50,0 \\
30,0\end{array}$ & $\begin{array}{l}79,4 \\
84,3 \\
85,4\end{array}$ \\
\hline Nitrofluorfen & $\begin{array}{l}0,25 \\
0,50 \\
0,75\end{array}$ & $\begin{array}{l}42,0 \\
58,0 \\
40,1\end{array}$ & $\begin{array}{l}60,3 \\
69,9 \\
90,4\end{array}$ & $\begin{array}{r}0,0 \\
55,5 \\
35,2\end{array}$ & $\begin{array}{l}53,6 \\
56,1 \\
43,9\end{array}$ & $\begin{array}{r}35,3 \\
32,3 \\
0,0\end{array}$ & $\begin{array}{l}40,1 \\
57,4 \\
46,1\end{array}$ \\
\hline $\begin{array}{c}\text { Pendimethalin (Formulaçäo } \\
\text { brasileira) }\end{array}$ & 1,20 & 80,2 & 92,0 & 78,4 & 64,5 & 32,4 & 75,8 \\
\hline $\begin{array}{c}\text { Pendimethalln (Formulaçäo } \\
\text { americana) }\end{array}$ & 1,20 & 84,5 & 82,2 & 62,5 & 53,6 & 20,6 & 71,4 \\
\hline Trifluralin(*) & 1,00 & 94,4 & 100,0 & 88,9 & 0,0 & 0,0 & 75,3 \\
\hline Trifluralin(**) & 1,00 & 93,8 & 100,0 & 94,4 & 17,1 & 0,0 & 77,8 \\
\hline $\begin{array}{c}\text { Nitrofluorfen } \\
+ \\
\text { trifluralin( }\end{array}$ & $0,25+0,50$ & 99,3 & 100,0 & 88,9 & 46,3 & 20,6 & 84,3 \\
\hline Testemunha $\left({ }^{* * *}\right)$ & - & 162 & 73 & 54 & 41 & 34 & 364 \\
\hline
\end{tabular}

(*) Usado na formulação de Treflan

(**) Usado na formulação de Triflurex

(***) Número de plantas daninhas por metro quadrado.

Quadro 7. Porcentagem de controle, 30 dias após a aplicação dos herbicidas em pré-plantio incorporado, em ensaio com algodão, em Araras, SP.

\begin{tabular}{|c|c|c|c|c|c|}
\hline \multirow[b]{2}{*}{ Herbicidn } & \multirow{2}{*}{$\begin{array}{l}\text { Ingrediente } \\
\text { ativo } \\
\text { (kg/ha) }\end{array}$} & \multicolumn{4}{|c|}{ Porcentagem de controle } \\
\hline & & $\begin{array}{l}\text { Digiteria } \\
\text { horizontalis }\end{array}$ & $\begin{array}{l}\text { Blatnvilled } \\
\text { rhomboidea }\end{array}$ & $\begin{array}{c}\text { Emilia } \\
\text { sonchifolla }\end{array}$ & Controle getal \\
\hline Diethatyl & $\begin{array}{l}2,00 \\
4,00 \\
6,00\end{array}$ & $\begin{array}{r}90,0 \\
98,0 \\
100,0\end{array}$ & $\begin{array}{l}38,6 \\
40,9 \\
42,0\end{array}$ & $\begin{array}{r}4,8 \\
14,3 \\
4,8\end{array}$ & $\begin{array}{l}45,0 \\
50,5 \\
49,4\end{array}$ \\
\hline Nitrofluorfen & $\begin{array}{l}0,25 \\
0,50 \\
0,75\end{array}$ & $\begin{array}{l}56,0 \\
60,0 \\
80,0\end{array}$ & $\begin{array}{l}18,1 \\
14,7 \\
23,8\end{array}$ & $\begin{array}{l}9,5 \\
4,8 \\
9,5\end{array}$ & $\begin{array}{l}26,6 \\
25,0 \\
36,1\end{array}$ \\
\hline $\begin{array}{c}\text { Pendimethalln (Formulação } \\
\text { brasilletra) }\end{array}$ & 1,20 & 86,0 & 47,7 & 9,5 & 49,4 \\
\hline $\begin{array}{r}\text { Pendimethalln (Formulação } \\
\text { americana) }\end{array}$ & 1,20 & 84,0 & 57,9 & 14,3 & 55,0 \\
\hline $\begin{array}{l}\text { Trifluralin(*) } \\
\text { Trifluralin(**) }\end{array}$ & $\begin{array}{l}1,00 \\
1,00\end{array}$ & $\begin{array}{l}96,0 \\
98,0\end{array}$ & $\begin{array}{r}10,2 \\
0,3\end{array}$ & $\begin{array}{l}0,0 \\
4,8\end{array}$ & $\begin{array}{l}30,5 \\
30,0\end{array}$ \\
\hline $\begin{array}{l}\text { Nitrofluorfen } \\
\qquad+ \\
\text { trifluralin(*) } \\
\text { Testemunha }(* *)\end{array}$ & $\begin{array}{c}0,25+0,50 \\
-\end{array}$ & $\begin{array}{l}90,0 \\
50\end{array}$ & $\begin{array}{l}44,3 \\
88\end{array}$ & $\begin{array}{r}0,0 \\
42\end{array}$ & $\begin{array}{l}40,0 \\
180\end{array}$ \\
\hline
\end{tabular}

(*) Usado na formulaçăo de Treflan

(**) Usado na formulaçăo de Trefhurex

(***) Número de plantas daninhas por metro quadrado. 
Quadro 8. Número de plantas e produção de algodão em caroço em ensaios bom herbicidas em pré-plantio incorporado, em Pirassununga, SP, e em Araras, SP.

\begin{tabular}{|c|c|c|c|c|c|}
\hline \multirow[b]{2}{*}{ Herbicida } & \multirow{2}{*}{$\begin{array}{l}\text { Ingrediente } \\
\text { ativo } \\
\text { (Kg/ha) }\end{array}$} & \multicolumn{2}{|c|}{ Pirnssununge } & \multicolumn{2}{|c|}{ Anras } \\
\hline & & $\begin{array}{l}\text { Número de } \\
\text { phantas }\end{array}$ & $\begin{array}{l}\text { Produçīo } \\
\text { (kq) }\end{array}$ & $\begin{array}{l}\text { Número de } \\
\text { phntas }\end{array}$ & $\begin{array}{l}\text { Producio } \\
\text { (kg) }\end{array}$ \\
\hline Diethatyl & $\begin{array}{l}2,00 \\
4,00 \\
6,00\end{array}$ & $\begin{array}{l}693 \\
652 \\
673\end{array}$ & $\begin{array}{l}11,500 \\
12,250 \\
11,000\end{array}$ & $\begin{array}{l}644 \\
635 \\
649\end{array}$ & $\begin{array}{l}9,000 \\
9,500 \\
9,750\end{array}$ \\
\hline Nitrofluorfen & $\begin{array}{l}0,25 \\
0,50 \\
0,75\end{array}$ & $\begin{array}{l}681 \\
675 \\
673\end{array}$ & $\begin{array}{l}11,750 \\
11,500 \\
11,500\end{array}$ & $\begin{array}{l}654 \\
639 \\
642\end{array}$ & $\begin{array}{r}9,500 \\
9,500 \\
10,000\end{array}$ \\
\hline $\begin{array}{c}\text { Pendimethalin (Formulação } \\
\text { brasileira) }\end{array}$ & 1,20 & 669 & 11,250 & 626 & $.9,250$ \\
\hline $\begin{array}{r}\text { Pendimethalin (Formulação } \\
\text { americana) }\end{array}$ & 1,20 & 671 & 12,250 & 631 & 9,750 \\
\hline Trifluralin(*) & 1,00 & 670 & 12,250 & 620 & 9,750 \\
\hline Trifluralin(**) & 1,00 & 682 & 11,750 & 617 & 9,500 \\
\hline $\begin{array}{c}\text { Nitrofluorfen } \\
+ \\
\text { triflumalin( }\end{array}$ & $0,25+0,50$ & 669 & 12,000 & 648 & 9,250 \\
\hline Testemunha & - & 675 & 11,250 & 633 & 9,250 \\
\hline
\end{tabular}

(*) Usado na formulação de Treflan

(**) Usado na formulação de Triflurex

Quadro 9. Porcentagem de controle, 30 dias após a aplicação dos herbicidas em pré-plantio incorporado e em pré-emergência, em ensaio com algodão em Mogi-Mirim, SP.

\begin{tabular}{|c|c|c|c|c|c|c|c|}
\hline \multirow[b]{2}{*}{ Herbicida } & \multirow{2}{*}{$\begin{array}{c}\text { Ingrediente } \\
\text { ativo } \\
\text { (kg/ha) }\end{array}$} & \multicolumn{5}{|c|}{ Porcentagem de controle } & \multirow[b]{2}{*}{$\begin{array}{l}\text { Controle } \\
\text { genl }\end{array}$} \\
\hline & & $\begin{array}{l}\text { Elewsine } \\
\text { Andica }\end{array}$ & $\begin{array}{l}\text { Acanthos- } \\
\text { permum } \\
\text { hispidum }\end{array}$ & $\begin{array}{c}\text { Emilia } \\
\text { sonchifolis }\end{array}$ & $\begin{array}{l}\text { Commeline } \\
\text { elegans }\end{array}$ & $\begin{array}{l}\text { Ipomoed } \\
\text { sp }\end{array}$ & \\
\hline Diethaty $x^{(*)}$ & $\begin{array}{l}2,00 \\
4,00 \\
6,00\end{array}$ & $\begin{array}{r}78,1 \\
100,0 \\
99,2\end{array}$ & $\begin{array}{l}52,3 \\
72,2 \\
75,8\end{array}$ & $\begin{array}{r}0,0 \\
70,0 \\
77,5\end{array}$ & $\begin{array}{l}60,0 \\
60,0 \\
56,7\end{array}$ & $\begin{array}{l}0,0 \\
6,6 \\
0,0\end{array}$ & $\begin{array}{l}50,6 \\
73,4 \\
75,9\end{array}$ \\
\hline Diethaty $(* *)$ & $\begin{array}{l}2,00 \\
4,00 \\
6,00\end{array}$ & $\begin{array}{r}91,4 \\
98,4 \\
100,0\end{array}$ & $\begin{array}{l}36,3 \\
69,6 \\
79,8\end{array}$ & $\begin{array}{l}67,5 \\
70,0 \\
70,0\end{array}$ & $\begin{array}{l}30,0 \\
66,6 \\
63,3\end{array}$ & $\begin{array}{r}6,6 \\
16,6 \\
26,6\end{array}$ & $\begin{array}{l}44,1 \\
71,8 \\
79,9\end{array}$ \\
\hline Alachlor $\left.{ }^{*}\right)$ & 2,50 & 100,0 & 92,3 & 72,5 & 80,0 & 60,0 & 95,5 \\
\hline Triflurallin $(* *)$ & 1,00 & 99,2 & 60,4 & 2,5 & 56,7 & 0,0 & 60,9 \\
\hline Testemunha $(* * *)$ & - & 128 & 694 & 40 & 30 & 30 & 922 \\
\hline
\end{tabular}

(*) Aplicado em pró-emergência

(*.) Aplicado em pro-plantio incorporado

(***) Número de plantas dantnhas por metro quadrado. 
QUADRO 10. Número de plantas e produção de algodão em caroço em ensaio com herbicidas em pré-plantio incorporado e em pré-emergência, em Mogi-Mirim, SP.

\begin{tabular}{|c|c|c|c|}
\hline Herbicida & $\begin{array}{l}\text { Ingrediente } \\
\text { ativo } \\
\text { (kg/ha) }\end{array}$ & $\begin{array}{l}\text { Número de } \\
\text { plantas }\end{array}$ & $\begin{array}{c}\text { Produçio } \\
\text { (kg) }\end{array}$ \\
\hline Dlethatyl ${ }^{(*)}$ & $\begin{array}{l}2,00 \\
4,00 \\
6,00\end{array}$ & $\begin{array}{l}569 \\
572 \\
581\end{array}$ & $\begin{array}{l}7,250 \\
7,500 \\
7,500\end{array}$ \\
\hline Diethatyl $\left({ }^{* *}\right)$ & $\begin{array}{l}2,00 \\
4,00 \\
6,00\end{array}$ & $\begin{array}{l}567 \\
590 \\
576\end{array}$ & $\begin{array}{l}8,000 \\
7,500 \\
7,500\end{array}$ \\
\hline Alachlor ${ }^{(*)}$ & 2,50 & 589 & 7,750 \\
\hline Trifluralim $\left.{ }^{(* *}\right)$ & 1,00 & 574 & 8,000 \\
\hline Testemunha & - & 578 & 7,500 \\
\hline
\end{tabular}

(*) Aplicado em pré-emergêncta

(**) Aplicado em pré-plantio incorporado

um fator considerável de influência na ação dos herbicidas experimentados.

Alguns autores $(\mathbf{1 3}, \mathbf{1 4})$ afirmam que qualquer fator que afete os microorganismos do solo, entre os quais está a matéria orgânica, afetará a atividade dos herbicidas. Kearney e Kaufman (12) mencionam a influência da matéria or- gânica na decomposição de trifluralin e compostos relativos. Nos experimentos, a variação do teor de matéria orgânica contida nos solos estava entre 2,50 e $5,50 \%$. Houve variação ainda no teor de argila de 32,50 a $65,00 \%$, significativa, portanto, em influenciar a ação dos herbicidas.

Admitindo as possiveis influências dos fatores atrás considerados, sobre os resultados obtidos, pode-se dizer que diethatyl controlou eficientemente as seguintes dicotile dôneas quando usado a $3,00 \mathrm{~kg}$ e $4,00 \mathrm{~kg} / \mathrm{ha}$, em préemergência: A. conyzoides, B. alata, $R$. brasiliensis e Sida spp. Em pré-plantio incorporado controlou eficientemente $R$. brasiliensis e regularmente $B$. alata e Sida spp. Quando empregado a 6,00 $\mathrm{kg} / \mathrm{ha}$, em pré-emergência, controlou ainda, regularmente, A. hispidum, $B$. pilosa, e E. sonchifolia. Nesta dose, em pré-plantio incorporado, controlou regularmente $E$. sonchifolia.

Considerando o conjunto dos experimentos, as doses de 3,00 kg e 4,00 kg/ ha de diethatyl ofereceram resultados economicamente melhores quando comparadas com outras.

Comparando a ação de diethatyl com os outros herbicidas testados, ele foi superior a nitrofluorfen; e, em pré-

Quadro 11. Porcentagem de controle, 30 dias após a aplicaçã o dos herbicidas em pré-plantio incorporado e em pré-emergência, em ensaio com algodão em Pirassununga-SP.

\begin{tabular}{|c|c|c|c|c|c|c|}
\hline \multirow[b]{2}{*}{ Herbicida } & \multirow{2}{*}{$\begin{array}{l}\text { Ingrediente } \\
\text { ativo } \\
(\mathrm{kg} / \mathrm{ha})\end{array}$} & \multicolumn{5}{|c|}{ Porcentagem de controle } \\
\hline & & $\begin{array}{l}\text { Digitarla } \\
\text { Horizontalis }\end{array}$ & $\begin{array}{l}\text { Ageratum } \\
\text { conyzoides }\end{array}$ & Sida spp & $\begin{array}{l}\text { Richandia } \\
\text { brasiliensis }\end{array}$ & Controle geral \\
\hline Diethaty $\left(^{(*)}\right.$ & $\begin{array}{l}2,00 \\
3,00 \\
4,00\end{array}$ & $\begin{array}{r}93,0 \\
100,0 \\
100,0\end{array}$ & $\begin{array}{l}74,9 \\
82,9 \\
83,4\end{array}$ & $\begin{array}{l}73,3 \\
89,6 \\
94,0\end{array}$ & $\begin{array}{r}93,7 \\
100,0 \\
100,0\end{array}$ & $\begin{array}{l}77,2 \\
87,9 \\
89,8\end{array}$ \\
\hline Diethaty $\left({ }^{* *}\right)$ & $\begin{array}{l}2,00 \\
3,00 \\
4,00\end{array}$ & $\begin{array}{l}48,8 \\
44,2 \\
79,1\end{array}$ & $\begin{array}{r}10,2 \\
0,0 \\
42,8\end{array}$ & $\begin{array}{l}62,2 \\
79,2 \\
68,9\end{array}$ & $\begin{array}{r}0,0 \\
0,0 \\
12,5\end{array}$ & $\begin{array}{r}31,0 \\
0,0 \\
54,8\end{array}$ \\
\hline Alachlor ${ }^{(*)}$ & 2,50 & 97,7 & 92,5 & 96,3 & 100,0 & 94,7 \\
\hline Trifluralin $(* *)$ & 1,00 & 93,0 & 0,0 & 31,8 & 56,2 & 13,6 \\
\hline Testemunha $(\bullet * *)$ & - & 43 & 187 & 135 & 16 & 381 \\
\hline
\end{tabular}

(*) Aplicado em préemengência

(*) Aplicado em pró-plantio incorporado

$(* * *)$ Número de plantas daninhas por metro quadrado. 
Quadro 12. Porcentagem de controle, 30 dias após a aplicação dos herbicidas, em pré-plantio incorporado e em pré-emergência, em ensaio com algodão em Casa Branca, SP.

\begin{tabular}{|c|c|c|c|c|c|c|c|}
\hline \multirow[b]{2}{*}{ Henticide } & \multirow{2}{*}{$\begin{array}{l}\text { Ingrediente } \\
\text { ativo } \\
\text { (ke/ha) }\end{array}$} & \multicolumn{4}{|c|}{ Porcentagem de controle } & \multirow[b]{2}{*}{ Sida spp } & \multirow[b]{2}{*}{$\begin{array}{c}\text { Controle } \\
\text { geral }\end{array}$} \\
\hline & & $\begin{array}{c}\text { Digitoriz } \\
\text { hortzontalis }\end{array}$ & $\begin{array}{l}\text { Richurdis } \\
\text { bratiliensts }\end{array}$ & $\begin{array}{l}\text { Bomeria } \\
\text { alata }\end{array}$ & $\begin{array}{l}\text { Acanthos- } \\
\text { permum } \\
\text { eustrile }\end{array}$ & & \\
\hline Diethaty $(*)$ & $\begin{array}{l}2,00 \\
3,00 \\
4,00\end{array}$ & $\begin{array}{l}72,9 \\
73,9 \\
85,7\end{array}$ & $\begin{array}{l}23,6 \\
53,9 \\
53,8\end{array}$ & $\begin{array}{l}73,4 \\
88,4 \\
98,7\end{array}$ & $\begin{array}{l}0,0 \\
0,0 \\
0,0\end{array}$ & $\begin{array}{l}46,9 \\
73,5 \\
67,3\end{array}$ & $\begin{array}{l}49,7 \\
61,9 \\
66,6\end{array}$ \\
\hline Diethaty $\left({ }^{* *}\right)$ & $\begin{array}{l}2,00 \\
3,00 \\
4,00\end{array}$ & $\begin{array}{l}30,9 \\
38,3 \\
43,4\end{array}$ & $\begin{array}{l}4,4 \\
0,0 \\
1,5\end{array}$ & $\begin{array}{l}64,3 \\
66,0 \\
79,7\end{array}$ & $\begin{array}{r}12,4 \\
0,0 \\
0,0\end{array}$ & $\begin{array}{l}44,9 \\
55,1 \\
63,3\end{array}$ & $\begin{array}{l}24,8 \\
24,2 \\
29,3\end{array}$ \\
\hline Ahchlor $\left.{ }^{*}\right)$ & 2,50 & 61,4 & 57,7 & 88,4 & 35,7 & 75,5 & 61,0 \\
\hline Trifumalin $(* *)$ & 1,00 & 97,6 & 88,2 & 97,1 & 11,9 & 18,4 & 85,3 \\
\hline Testemunha $(\bullet \bullet \bullet)$ & - & 1107 & 723 & 241 & 210 & 49 & 2330 \\
\hline
\end{tabular}

(*) Aplicado em próemergêncta

(*) Aplicado em pat-plantio tncorporado.

(**) Número de plantas daninhas por metro quadrado.

Quadro 13. Número de plantas e produção de algodão em caroço em ensaios com herbicidas em pré-plantio incorporado e em pré-emergência, em Pirassununga, SP e em Casa Branca, SP.

\begin{tabular}{|c|c|c|c|c|c|}
\hline \multirow[b]{2}{*}{ Herbicidn } & \multirow{2}{*}{$\begin{array}{l}\text { Ingrediente } \\
\text { ativo } \\
\text { (k\&/ha) }\end{array}$} & \multicolumn{2}{|c|}{ Prasumun } & \multicolumn{2}{|c|}{ Can Branca } \\
\hline & & $\begin{array}{c}\text { Númeso de } \\
\text { plantas }\end{array}$ & $\begin{array}{l}\text { Produçio } \\
\text { (k\&) }\end{array}$ & $\begin{array}{c}\text { Número de } \\
\text { phntas }\end{array}$ & $\begin{array}{l}\text { Produço } \\
\text { (kg) }\end{array}$ \\
\hline Diethaty $\left(^{(\bullet)}\right.$ & $\begin{array}{l}2,00 \\
3,00 \\
4,00\end{array}$ & $\begin{array}{l}265 \\
267 \\
258\end{array}$ & $\begin{array}{l}6,750 \\
6,750 \\
6,750\end{array}$ & $\begin{array}{l}321 \\
324 \\
318\end{array}$ & $\begin{array}{l}9,000 \\
9,000 \\
9,250\end{array}$ \\
\hline Diethaty $\left(\mathbf{1}^{* *}\right)$ & $\begin{array}{l}2,00 \\
3,00 \\
4,00\end{array}$ & $\begin{array}{l}261 \\
260 \\
255\end{array}$ & $\begin{array}{l}6,750 \\
7,250 \\
6,500\end{array}$ & $\begin{array}{l}317 \\
315 \\
316\end{array}$ & $\begin{array}{l}9,500 \\
9,500 \\
9,500\end{array}$ \\
\hline Alachlor ${ }^{(\bullet)}$ & 2,50 & 266 & 6,375 & 319 & 9,500 \\
\hline Triflunalin $(* *)$ & 1,00 & 258 & 6,750 & 320 & 8,750 \\
\hline Testemunha & - & 273 & 6,750 & 318 & 9,250 \\
\hline
\end{tabular}

(*) Aplicado em pró-emergêncla

(**) Aplicado em pro-plantlo incorporado 
Quadro 14. Temperatura a 1,00 acima do solo, a 0,025 , a 0,050 e a 0,100 de profundidade do solo por ocasião da aplicação de herbicidas em sete ensaios com algodão.

\begin{tabular}{lllll} 
& \multicolumn{4}{c}{ Tempentums } \\
\cline { 2 - 5 } Experimento & $\begin{array}{l}1,00 \mathrm{~m} \\
\left({ }^{\circ} \mathrm{C}\right)\end{array}$ & $\begin{array}{l}\mathbf{0 , 0 2 5 \mathrm { m }} \\
\left({ }^{\circ} \mathrm{C}\right)\end{array}$ & $\begin{array}{l}\mathbf{0 , 0 5 0 \mathrm { m }} \\
\left({ }^{\circ} \mathrm{C}\right)\end{array}$ & $\begin{array}{l}\mathbf{0 , 1 0 0 \mathrm { m }} \\
\left({ }^{\circ} \mathrm{C}\right)\end{array}$ \\
\hline 1 & 33,0 & 43,0 & 33,5 & 30,0 \\
2 & 31,0 & 33,2 & 27,8 & 24,8 \\
3 & 23,0 & 22,2 & 20,4 & 17,5 \\
4 & 28,5 & 27,4 & 24,0 & 23,2 \\
$5\left(^{*}\right)$ & 34,2 & 37,2 & 32,8 & 27,4 \\
$5\left(^{*}\right)$ & 34,8 & 38,4 & 33,2 & 32,0 \\
$6\left(^{*}\right)$ & 22,2 & 22,4 & 21,8 & 21,5 \\
$6\left(^{* *}\right)$ & 26,5 & 29,4 & 23,8 & 23,2 \\
$7\left(^{*}\right)$ & 29,5 & 32,1 & 28,0 & 27,5 \\
$7\left(^{* *}\right)$ & 32,2 & 33,8 & 31,2 & 30,4 \\
\hline \hline
\end{tabular}

(*) Medição realtzada antes da aplicaçẫo dos herbłcidas em pré-plantio incorporado.

(**) Medição realizada antes da aplicação dos herbicidas em pró-emergência.

plantio incorporado, foi semelhante à mistura de nitrofluorfen com trifluralin. Foi ainda, um pouco superior a pendimethalin. Quando usado em pré-emergencia, foi semelhante a alachlor.

Nenhum dos herbicidas testados foi prejudicial ao desenvolvimento vegetativo dos algodoeiros e à produção de algodão em caroço.

\section{LITERATURA CITADA}

1. Alves, A. \& Forster, R. - Variaçóes nos métodos de aplicação dos herbicidas Diuron e Trifluralin na cultura do algodoeiro. In: Sem. Bras. Herb. Ervas Dan., 6. ${ }^{\circ}$, Sete Lagoas, 1966. Anais. 1968, p.51-63.

2. Berumen, H. \& Leopoldo, P.R. - Uso do Herban como herbicida seletivo post-emergence na cultura do algodoeiro. In: Sem. Bras. Herb. Ervas Dan., 6. ', Sete Lagoas, 166. Anais, 1968, p.313.

3. Blanco, H.G. \& Godoy, H. - Cartas das chuvas do Estado de Sáo Paulo. Sảo Paulo, Insti. tuto Agronómico, 1967.

4. Blanco, H.G. \& Oliveira, D.A. - Contribulçáo para determinaçáo do periodo de competiçáo das plantas daninhas na cultura do algodáo (Gossypium hirsutum L.). Biológico 42 (9-10): 201-205, 1976.

5. Buchanan, G.A. \& Burns, E.R. - Influence of weed competition on cotton. Weed Science, 18: $149 / 154,1970$

6. Buendia, J.P.L.: Penna, J.C.V. \& Ferreira, M B. - Competiçáo de herbicidas na cultura algodoeira (Gassypium hirsutum L.) no Triânguo Mineiro. In: Sem. Bras. Herb. Ervas Dan., $10^{\circ}$, Santa Maria, 1974. Resumos, p.15.

7. Cruz, L.S.P. \& Leiderman, L. - Primeiros estudos comparativos do efeito herbicida de fluchloralin e dinitramine para algodoeiro. Biológico 40: 314-320, 1974.

8. Cruz, L.S.P. \& Leiderman. L. - Efeitos do novo herbicida HP 412 no controle de algumas plantas daninhas em cultura de algodáo (Gossypium hirsutum L.). Biológico 44: 93-11, 1978.

9. Ferraz, C.A.M. Deuber, R.; Cla, E.; Leitáo Filho, H.F.; Aranha, C.; Sabino, N.P.; Forster, R. \& Veiga, A.A. Efeitos de plantas invasoras na cultura algodoeira. In: Sem. Bras. Herb. Ervas Dan., 9:- Campinas, 1972. Resumos, p.11.

10. Forster, R. - Um novo herbicida a base de 2chloro-2',6'-diethyl-N-(Metoxy methyl) acetanilide (CP 50144) para amendoim. In: Sem. Bras. Herb. Ervas Dan., 6. ${ }^{\circ}$, Sete Lagoas, 1966. Anais, 1968. p.73-84.

11. Kasasian, L. \& Seeyave, J. Critical periods for weed competition. Pans 15: 208-215, 1959.

12. Kearney, P.C. \& Kaufman, D.D. - Degradation of herbicides. Marcel Dekker Inc., New York, 1969. 394p.

13. Klingman G.C. - Weed Control: as a science. Lyman J. Noordhoff, New York, 1961. 421p.

14. Lamar, R.V. - Control de malezas. 2.a ediçáo Universidad Catolica de Chile. Santiago de Chile, 1971. 242p

15. Santos, C.A.L.; Leiderman, L. \& Figueiredo, P. - Ensaios comparativos entre Cotoran novo herbicida à base de Uréia, Diuron e Tri fluralin na cultura do algodáo. Biológico, 34: $12-16,1968$

16. Santos, C.A.L. - Aplicaçảo de herbicidas em pré-plantio e pré-emergência na cultura do algodảo. In: Sem. Bras. Herb. Ervas Dan., 8. Botucatu, 1970. Resumos, p.IX-02.

17. Splittstoesser, W.E. \& Derscheid, C.A. Effects of environment upon herbicides applied preemergence. Weeds 10: 304-307, 1962. 